\title{
Prática pedagógica e relação professor-aluno em cursinhos
}

Práctica pedagógica y relación profesor-alumno en los cursos preparatorios

Pedagogical practice and teacher-student relationship in preparatory courses

Celso Francisco Tondin

Universidade Federal de São João Del-Rei-Minas Gerais - Brasil

Larissa Medeiros Marinho dos Santos

Universidade Federal de São João Del-Rei - Minas Gerais - Brasil

Deruchette Danire Henriques Magalhães

Universidade Federal de São João Del-Rei-Minas Gerais - Brasil

Jacqueline Danielle Pereira

Universidade Federal de São João Del-Rei-Minas Gerais - Brasil

\section{RESUMO}

Instituições que oferecem cursos preparatórios para vestibulares, Exame Nacional do Ensino Médio (ENEM) e concursos públicos, os conhecidos cursinhos, tornaram-se espaço de trabalho atrativo para os professores. Este estudo objetiva identificar, a partir de um cursinho, características dos alunos e conhecer a prática pedagógica e seus efeitos na relação professor-aluno. Trata-se de pesquisa exploratória realizada em uma instituição privada de uma cidade de pequeno porte do interior de Minas Gerais, com o uso da observação participante, com registro em diário de campo, e aplicação de questionário a 31 alunos. Com base na Análise do Conteúdo, os dados foram organizados em categorias. A primeira delas, características dos alunos, indica que a maioria é do sexo feminino, solteira, não trabalha, estuda em escola pública, pretende estudar em universidades públicas, mora com os pais em casa própria, em área urbana, com até mais três pessoas, tem renda familiar de um a seis salários mínimos e pelo menos um dos pais não concluiu o ensino médio. A segunda categoria, prática pedagógica e relação professor-aluno, informa que o trabalho docente acontece em condições favoráveis à medida que as estratégias didáticas adotadas nos cursinhos, baseadas na memorização e na descontração, resultam em maior interesse dos estudantes e na aproximação entre os corpos docente e discente. Pelo fato de ambos cooperarem com o foco na almejada aprovação em processos seletivos incrementa-se uma marca pragmática e utilitarista no processo ensino-aprendizagem.

Palavras-chave: Cursinho. Prática pedagógica. ENEM. Vestibular. 


\title{
RESUMEN
}

Las instituciones que ofrecen cursos preparatorios para vestibulares, Examen Nacional de la Enseñanza Media (ENEM) y concursos públicos, los conocidos cursillos, se convirtieron en un espacio de trabajo atractivo para los profesores. Este estudio objetiva identificar, a partir de un cursillo, características de los alumnos, conocer la práctica pedagógica y sus efectos en la relación profesor-alumno. Se trata de una investigación exploratoria realizada en una institución privada de una ciudad pequeña del interior de Minas Gerais, con el uso de la observación participante, registro en diario de campo, y aplicación de cuestionario a 31 alumnos. A partir del análisis del contenido, los datos se organizaron en categorías. La primera de ellas, características de los alumnos, indica que la mayoría es del sexo femenino, soltera, no trabaja, estudia en escuela pública, pretende estudiar en universidades públicas, vive con los padre, en área urbana, con hasta tres personas, tiene ingresos familiares de uno a seis salarios mínimos y por lo menos uno de los padres no concluyó la enseñanza media. La segunda categoría, práctica pedagógica y relación profesor-alumno, informa que el trabajo docente ocurre en condiciones favorables a medida que las estrategias didácticas adoptadas en los cursillos, basadas en la memorización y en la relajación, resultan en mayor interés de los estudiantes y en la aproximación entre los cuerpos docente y discente. Por el hecho de que ambos cooperan con el foco en la anhelada aprobación en procesos selectivos se incrementa una marca pragmática y utilitarista en el proceso enseñanza-aprendizaje.

Palabras-clave: Curso preparatorio. Práctica pedagógica. ENEM. Vestibular.

\begin{abstract}
Institutions that offer entrance exams preparatory courses, like The National High School Examination (ENEM) and public tenders, have become an attractive space for teachers. This study aims to identify, from a preparatoy course, the students characteristics and the pedagogical practice and their effects on the teacher-student relationship. This exploratory research was carried out in a small hinterland city private institution of Minas Gerais State, with the use of participant observation, field diary records and 31 students interviews. Based on Content Analysis, data were organized into categories. The first one, characteristics of the students, indicates that the majority is female, single, does not work, studies in public school, intends to study in public colleges, lives with their parents in private houses, in urban areas, with up to three or more people, has a family one-to-six minimum salaries and at least one of the parents did not finish high school. The second category, pedagogical practice and teacher-student relationship, reports that teaching takes place in favorable conditions as the didactic strategies adopted in courses, based on memorization and relaxation, result in greater interest from students and the approximation of teachers and students boards. Because both cooperate to the approval in selective processes, there is an increasement in the pragmatic and utilitarian teaching-learning process.
\end{abstract}

Keywords: Preparatory course. Pedagogical practice. ENEM. Entrance exam.

\section{Introdução}

Entre as décadas de 1950 e 1960, aconteceu no Brasil a criação de um exame específico para a entrada em cada faculdade (Pezzi, 2002). Em 68, a Lei n. 5540, da reforma universitária, dispunha sobre a formação de departamentos nos centros universitários, provas classificatórias, entre outras proposições (Silva, 2012). Contudo, não foi em 50 que os cursinhos surgiram. Seu nascimento está coadunado com o do vestibular, que se deu, na sua forma inicial (os exames de estudos preparatórios, como citados acima), aproximadamente em 1910, época em 
que foram introduzidas as provas de admissão ao terceiro grau no país; que seriam, posteriormente em 1915, chamados de exames vestibulares, depois da Reforma Carlos Maximiliano na educação (Bonfim, 2003).

É nesse período que aparece a "semente" dos cursos preparatórios para vestibulares - que, contemporaneamente, são conhecidos e referidos como cursinhos -, tendo em vista que já na década de 1920 a quantidade de vagas no ensino superior não atendia o número de aspirantes (Guimarães, 1984), realidade que até hoje perdura, como informa Silva (2012). No ano de 1925, a Reforma de Ensino Rocha Vaz instaurou, em um de seus artigos, que haveria para os concorrentes a vagas na Escola Politécnica aulas de revisão e aprofundamento das matérias pertinentes à prova da escola citada (Guimarães, 1984). Pouco depois, vieram os cursinhos que preparavam para as provas que davam acesso aos cursos de Medicina, Direito e Filosofia (Whitaker, Paiva \& Onofre, 2008). Atualmente, além dos vestibulares, os cursinhos preparam para o Exame Nacional do Ensino Médio (ENEM) e concursos públicos.

Estudos realizados por Abramovay e Castro (2003) apontam que boa parte dos profissionais que atuam na rede pública de ensino do Brasil não tem as devidas condições de trabalho. Nesse sentido, apesar de sua importância para o crescimento e estimulação de seus alunos, muitas vezes o professor se depara com recursos escassos para trabalhar e falta envolvimento da escola, da família e da comunidade. Esses fatores transformam $\mathbf{o}$ professor, principalmente o da rede pública de ensino, em "vilão", sendo taxado como incapaz de preparar seus alunos para os vestibulares e outros processos seletivos. Com isso, Santos (2004) pondera que, muitas vezes, o papel do professor é enfatizado como fator bastante importante para que o desempenho do aluno seja cada vez mais eficiente, atingindo, assim, objetivos e metas que este traçou para sua vida escolar.
Tendo em vista essa constatação de que boa parte dos profissionais da rede pública de ensino não dispõe das devidas condições de trabalho e, em contrapartida, há uma exaltação dos cursos pré-vestibulares, Abramovay e Castro (2003) apontam uma crescente valorização dos professores que trocam as salas de aula de escolas para as salas de aula dos cursinhos. Essa escolha acarreta em mudanças na postura, na identidade e na relação professor-aluno (Bacchetto, 2003). O professor do cursinho é regido na maioria das vezes por um sistema de ensino privado, que disponibiliza o material e outros recursos, com $\mathrm{o}$ intuito de que ele indique aos alunos os melhores meios para aplicar os conceitos, fórmulas e conteúdos durante as provas de seleção (Santos, 2004).

Quais as grandes diferenças entre o trabalho do professor em escolas e em cursinhos? Segundo Bacchetto (2003), a primeira diferença está relacionada à constituição da instituição cursinho, que apesar de reconhecida como aparelho educacional, não se iguala à instituição escola.

eles não pertencem ao sistema oficial
de ensino e não são objeto de
políticas por parte do Estado; não
oferecem 'certificados' aos seus
concluintes; não são ponto terminal
de nenhuma etapa educacional, e sim
de preparação para outra; não
credenciam ao mercado de trabalho e
não têm qualquer fiscalização ou
controle por parte do Estado. (...)
embora não façam parte da rede
oficial, eles constituem um nível do
sistema educacional, opcional ou
compulsório, já
institucionalizado (Bacchetto, 2003,
p. 2).

Abramovay e Castro

(2003) consideram que, além disso, a metodologia de ensino adotada pelos professores também irá mudar de acordo com esses dois diferentes locais de trabalho. Geralmente, a imagem do professor da escola é relacionada à realização 
de provas, cobranças de atividades, disciplina na sala de aula e determinação de regras e horários. Sua aula é "sem graça". Por outro lado, o professor de cursinho tem sua imagem relacionada "à exposição, às resoluções de exercícios e ao estímulo à memorização" ( $p$. 174).

Segundo Santos (2004), essa realidade em que o cursinho ganha vantagem sobre a escola por causa de seu método "dinâmico" resulta que a escola seja vista como insuficiente e seus professores incapazes, o que acarreta uma série de problemas em relação à educação pública e impacta negativamente na busca dos alunos pelo ingresso nas universidades, uma vez que boa parcela deles não dispõe de meios para arcar com os custos de um curso pré-vestibular:

Pelos anúncios nos jornais vemos que em certas escolas mais procuradas 97\% dos candidatos aprovados são de um só cursinho! Em outras escolas vários cursinhos dividem entre si as vagas. Obviamente há muitos candidatos que fazem cursinho e não entram; mas são pouquíssimos os que entram sem cursinho. A primeira e grande seleção é, portanto sócioeconômica - só pode entrar na universidade quem tem condições de pagar e seguir um cursinho. (Hamburguer, 1970 citado por Bacchetto, 2003, p. 3-4).

Em virtude da atual conjuntura social e política do país, especificamente as propostas de alteração do sistema educacional, como a recém-aprovada reforma do Ensino Médio, o projeto de lei do "Programa Escola sem Partido" e os reiterados questionamentos quanto à lei de cotas (Lei no 12.711/2012), é necessário promover cada vez mais estudos em diferentes contextos educativos a fim de conhecer e problematizar as práticas pedagógicas engendradas nos cotidianos institucionais. Nesse sentido, é campo fecundo de discussão explorar como estão sendo constituídas as relações entre docentes e discentes nos cursinhos, buscando compreender quais os efeitos das práticas pedagógicas adotadas pelos professores na formação dos alunos. A partir dessa preocupação, o presente trabalho tem como objetivo identificar, a partir de um cursinho, características dos alunos e conhecer a prática pedagógica e seus efeitos na relação professoraluno.

Pesquisas dessa natureza podem contribuir com os profissionais que lidam direta ou indiretamente com educação e práticas pedagógicas, a fim de servir de referência para o entendimento acerca do trabalho desenvolvido não apenas nos cursos preparatórios para a Educação Superior, mas também para concursos públicos, que ocupam um espaço significativo no mercado educacional. Ou seja, é relevante a ampliação dos estudos e possíveis intervenções relacionadas a esse contexto e público, de modo a enriquecer a literatura sobre o tema e contribuir para uma formação das futuras gerações não apenas voltada para o mundo do trabalho, mas também para a cidadania, como apregoa a Lei de Diretrizes e Bases da Educação Nacional (LDBEN) (Lei $\mathrm{n}^{\circ}$ 9.394/1996).

Também para a Psicologia, de modo especial a Psicologia Escolar e Educacional, de base materialista histórico dialética, que se coloca no "compromisso ético-político com a emancipação humana" (Tanamachi \&Meira, 2003, p. 19), é relevante a presente investigação. Afinal, essa área de pesquisa e intervenção tem investido num projeto de sociedade que busca pensar, numa perspectiva crítica, os fenômenos que acontecem em instituições de cunho educativo, de modo a se pautar na "consideração dos determinantes sociais e dos aspectos subjetivos inerentes à organização escolar e à definição dos problemas de ensino-aprendizagem, visando a transformação do trabalho da escola." (p. 26).

\section{Método}

Trata-se de pesquisa exploratória cujo principal objetivo, tal como proposto 
por Gil (2008), é uma aproximação ao objeto com a intenção de conhecê-lo e construir hipóteses ou explicações. Geralmente, uma investigação desse tipo é precursora de outras mais abrangentes, pois suscita problematizações mais elaboradas ou hipóteses pertinentes para futuros estudos. Este método permite uma variedade de técnicas e as escolhidas foram a observação participante, com registro em diário de campo, e a aplicação de um questionário.

A observação participante, considerada uma técnica privilegiada para a compreensão do cotidiano escolar (Martins, 1996), pode ser compreendida como uma técnica que permite a observação e a participação do pesquisador, diminuindo a distância entre este e os participantes da pesquisa. Essa categoria de observação se define "como a técnica pela qual se chega ao conhecimento da vida de um grupo a partir do interior dele mesmo" (Gil, 2008, p. 10). Silva e Grigolo (2002, citados por Raupp \& Beuren, 2003) ressaltam que não necessariamente haverá uma atuação das partes, como é o caso da presente pesquisa. Ademais, Raupp e Beuren (2003) informam que o tema de estudo deve apontar para a base teórica que direcionará uma análise na qual as pessoas observadas são objeto central.

O diário de campo, comumente utilizado nos campos das ciências sociais e da educação, enquanto um método de registro das observações realizadas, além dos comentários, considerações e esclarecimentos dos pesquisadores (Roese, Gerhardt, Souza \& Lopes, 2006). Sua redação deve objetiva e sem interpretações pessoais que possam adulterar os fatos registrados, garantindo-lhe o caráter científico de sua redação (Falkembach, 1987).

E, finalmente, a aplicação de um questionário do tipo survey cuja intenção é de levantamento de dados, informações e crenças, a partir de um conjunto de perguntas (Günther,
2003).

A escolha da instituição se deu a partir do conhecimento dos seis cursos preparatórios existentes em uma cidade de pequeno porte do interior de Minas Gerais, sendo três deles de caráter privado e três de caráter comunitário. Optou-se por aquele mais próximo de uma universidade pública federal aonde atuam os(as) pesquisadores(as). Este critério foi adotado por indicar, além da proximidade geográfica, a vinculação entre a instituição (cursinho) e a Universidade. Além disso, há uma intensa mobilização afetiva dos alunos das turmas preparatórias para o ENEM no sentido de ingressarem nesta Universidade.

O cursinho em questão é uma iniciativa para suprir a escassez de cursos preparatórios, principalmente para a carreira militar, considerando que existe uma unidade do Exército de grande porte na cidade. Assim, inicialmente, a intenção dessa instituição era oferecer apenas cursos preparatórios para os concursos de ingresso em instituições militares e das Forças Armadas, sendo elas: Colégio Naval (CN), Escola Preparatória de Cadetes do Exército (EsPCEx), Escola Preparatória de Cadetes do Ar (EPCAR), Academia da Força Aérea (AFA), Escola de Formação de Oficiais da Marinha Mercante (EFOMM), Escola de Sargentos das Armas (EsSA), Escola de Especialistas da Aeronáutica (EEAR), Fuzileiros Navais (formação de soldado), Polícia Militar (formação de soldado) e Curso de Formação de Oficiais do Corpo de Bombeiros (CFO). Posteriormente, devido à grande demanda, passaram a oferecer cursos preparatórios para vestibulares e para o ENEM.

O cursinho pertence a dois sócios, caracterizando uma empresa familiar, e funciona nas dependências de uma escola privada que atua da Educação Infantil ao Ensino Médio no período matutino e vespertino. O cursinho aluga uma sala de aula no turno vespertino e nove salas no 
noturno.

A investigação foi realizada junto a duas turmas, que somam 41 alunos: a preparatória ao concurso público para ingresso no Curso de Formação de Oficiais do Corpo de Bombeiros (CFO), que conta com 27 alunos, o que corresponde a 65,9\% do total, e a denominada ENEM Intensivo Medicina, que tem 14 alunos, 34,1\%. Em ambas as turmas, o ensino das disciplinas está voltado exclusivamente à preparação para as provas de seleção/concurso público. A definição das turmas participantes deste estudo foi feita a partir de diálogo dos pesquisadores com a coordenação pedagógica do cursinho.

Em ambas as turmas foram realizadas quatro sessões de observação participante. Cada sessão durou uma hora e quarenta minutos, o que corresponde ao tempo de duas aulas. As aulas observadas na turma "ENEM Intensivo Medicina" corresponde às disciplinas de Física e Química, Matemática e Espanhol. E na turma "Curso de Formação de Oficiais do Corpo de Bombeiros (CFO)" foram observadas as aulas de Direitos Trabalhistas, Matemática, Geografia e Biologia.

Os dados e as problematizações produzidos nas observações foram registrados em diários de campo, separados em notas descritivas, em que se fez um relato amplo e detalhado dos fatos transcorridos, e em notas analíticas, nas quais se elaborava apontamentos e reflexões atinentes às situações observadas em interface com os intentos da pesquisa e sua base teórica.

O questionário foi disponibilizado na plataforma Google Forms (https://goo.gl/dE4auW) durante duas semanas, sendo respondido por 31 alunos, o que corresponde a $71,6 \%$ do total de convidados a respondê-lo (41 alunos). Não foi solicitada aos alunos que informassem a turma que frequenta, por isso os resultados são apresentados sem considerar especificidades das duas turmas. $\mathrm{O}$ instrumento envolvia questões sobre informações socioeconômicas dos alunos e de suas famílias, bem como questões relacionadas a sua opção de curso de graduação e universidade, atividades que ocupam seu tempo diário e sobre o sentimento de pressão para terem sucesso no concurso/ENEM por parte de si mesmos ou de suas famílias.

Além desses instrumentos, foram realizadas conversas informais com uma das proprietárias e com a coordenadora pedagógica do cursinho em diversos momentos, a fim de melhor contextualizar os dados e decidir sobre procedimentos deste estudo que dependiam da anuência da instituição e dos demais envolvidos, atendendo aos preceitos éticos em pesquisa.

Os dados de pesquisa foram organizados e analisados segundo os postulados da Análise do Conteúdo, de Bardin (2009), que é um conjunto sistematizado de técnicas para a análise do conteúdo de comunicações, neste caso os diários de campo e os questionários, e busca a categorização e análise das informações obtidas. Desse modo, foram estabelecidas duas seguintes categorias que se inter-relacionam: a) características dos alunos e b) prática pedagógica e relação professor-aluno.

\section{Resultados e discussão}

\section{Características dos alunos}

Tendo em vista que instituições educativas se justificam pelo intento da formação das futuras gerações, é fundamental conhecer quem são os estudantes que a frequentam. Nesse sentido, a Psicologia Escolar de perspectiva sócio-histórica sustenta a ideia de que os educadores precisam compreender o psiquismo e o desenvolvimento humano na sua interface com a aprendizagem escolar e as relações sociais estabelecidas no interior da escola e fora dela, a fim de conhecer os educandos e planejar o ensino de maneira mais adequada (Meira, 1998). Sendo assim, torna-se relevante 
apresentar algumas características dos alunos do cursinho que participaram deste estudo.

Dos 31 alunos que responderam ao questionário, 51,6\% eram mulheres; $96,8 \%$ deles eram solteiros e, como pudemos ver no ter contato com as turmas, a maioria era jovem; a maior parte dos estudantes mora em casa própria (da família) $(80,6 \%)$, em área urbana $(90,3 \%)$, com mais uma a três pessoas $(64,5 \%)$ e estes vivem com cerca de um a três salários mínimos $(38,7 \%)$ ou três a seis (25,8\%); uma média de $69,4 \%$ dos respondentes informa que pelo menos um dos seus pais não concluiu o ensino médio; $83,9 \%$ não trabalham e dos $17,1 \%$ que trabalham, $60 \%$ avaliam que o trabalho possibilitou o crescimento pessoal, $20 \%$ dizem que atrapalhou os estudos e outros $20 \%$ dizem que não atrapalhou; $54,8 \%$ deles estudaram todo o ensino fundamental e médio em escola pública.

Como verificado nas observações, na turma "ENEM Intensivo Medicina" as mulheres eram a maioria. Tal constatação se repetiu no questionário. Já na turma do CFO, ocorreu o oposto. Atestar essa maior presença das mulheres em uma turma preparatória para vestibulares confirma o fato de que, no Brasil, mais mulheres que homens vão para o ensino superior. Em 2015, 57,16\% do total de matrículas nas instituições de ensino superior eram femininas (Instituto Nacional de Estudos e Pesquisas Educacionais - INEP, 2015). Já nos concursos militares, a procura masculina é provavelmente maior devido ao número maior de vagas para homens do que para mulheres. Em 2014, por exemplo, as Forças Armadas contavam com aproximadamente $6 \%$ de mulheres, diante do efetivo total de 322.940 pessoas (Portal Brasil, 2014).

Quanto à predominância de solteiros e jovens no cursinho, isso demonstra o que já foi apontado por Silva (2012) sobre a "cara jovem" que esses espaços têm, seja prévestibular/ENEM ou preparatório para concursos.

Os dados referentes à renda mensal com a qual os estudantes e suas famílias vivem indicam que, possivelmente, a maioria das pessoas que respondeu ao questionário é do curso preparatório para os concursos militares, pois como se pode ver nas observações, grande parte dos alunos que frequentavam o ENEM/Medicina aparentava ser pelo menos de classe média.

Já a estatística referente à área na qual vivem os respondentes corrobora com os achados de Oliveira (2013), os quais demonstram que pessoas habitantes de urbanizações são as que mais prestam vestibulares; entretanto, o nível de industrialização da cidade até certo grau neutraliza o efeito da área urbana sobre a presença no vestibular. Isso condiz com a realidade da localização do cursinho, visto que é uma cidade, portanto, de área urbana mais expressiva do que a rural, mas seu desenvolvimento industrial não é tão grande quanto o de capitais e cidades de porte médio.

Os dados referentes à escolaridade dos pais ilustram o que os resultados da pesquisa de Bayma-Freire, Roazzi e Roazzi (2015) já haviam exposto: o nível de escolaridade dos pais pode intervir na continuidade do ciclo escolar dos filhos, "um problema prejudicial e de grandes repercussões nas classes desfavorecidas brasileiras" (p. 35).

Também, dentre os jovens que responderam ao questionário, $83,9 \%$ não trabalham, consequentemente $17,1 \%$ trabalham. Destes, como informado, 60\% avaliam que $\mathrm{o}$ trabalho possibilitou o crescimento pessoal e $20 \%$ dizem que atrapalhou os estudos e outros $20 \%$ dizem que não atrapalhou. Diante dos aspectos socioeconômicos constatados nas observações, este resultado já era esperado. Também na atualidade, com o prolongamento da adolescência e, consequentemente, o surgimento da nova fase da vida "adultojovem", que é quando os jovens já se tornaram adultos, mas ainda são dependentes em diferentes aspectos dos pais ou de um responsável (Vieira \&Rava, 2010), tem-se 
tornado mais comum que nessa fase da vida, nesse espaço "entre" a dependência infantil e as responsabilidades da vida adulta (Canevacci, 2008) esteja-se sob os cuidados de alguém e não inserido no mercado de trabalho.

Além disso, 54,8\% deles estudaram ou estudam todo o ensino fundamental e médio em escola pública. Este dado indica que, possivelmente, a maioria dos que responderam ao questionário era da turma "Curso de Formação de Oficiais do Corpo de Bombeiros (CFO)", visto que na turma "ENEM Intensivo Medicina" havia uma grande fração de alunos que estudava em escola particular, inclusive muitos na própria escola em que o cursinho funciona.

Nas perguntas sobre o que mais gostavam de fazer nas horas vagas e sobre as habilidades que creem ter, o que mais apareceu foi: esportes e estudar (incluindo ler). E em outra pergunta sobre a ocupação da maior parte do seu tempo livre, 45,2\% disseram ocupa-lo com internet; 25,8 com leitura e estudo; e $9,7 \%$, com TV.

Quando perguntados sobre qual tipo de Universidade pretendiam ingressar (pública ou privada), 51,6\% afirmaram que irão pleitear as vagas nas instituições públicas, enquanto $32,3 \%$ responderam que tentarão em ambas. Nenhum dos alunos escolheu a alternativa que dizia respeito à escolha apenas em instituições privadas. Os $16,1 \%$ restantes não pretendem ingressar em universidades, número que, temse como hipótese, diz respeito aos alunos da turma CFO, que participam de outros processos seletivos ao longo do ano. Estudos de Whitaker e Fiamengue (1999, 2001), Fiamengue (2002) e Whitaker (2010) apontam que a procura pelas universidades públicas é um movimento crescente e envolve principalmente os alunos que fizeram o ensino médio nas escolas estaduais e municipais; outro fator que pode influenciar a escolha é o fato de que a ideia de estar em uma universidade pública está vinculada ao maior "sucesso" na carreira.
Já no que se refere à escolha do curso superior, $61,3 \%$ dos alunos afirmaram ter alguma afinidade pessoal que fez com que se interessassem por determinada profissão; $16,1 \%$ responderam que sua escolha perpassa a possibilidade de contribuir com a sociedade com seus serviços prestados; e um dos alunos escolheu a alternativa que relacionava a escolha com o interesse familiar. Sabe-se que a escolha da profissão é um dos passos mais difíceis na vida de um jovem adulto, que passa a encarar o ingresso na Universidade como algo obrigatório e que irá direcionar todo o seu futuro. Segundo Nepomuceno e Witter (2010), a profissão é influenciada por diversos aspectos que envolvem o apoio ou desaprovação da família, o retorno financeiro, $\mathrm{o}$ atendimento à comunidade, entre outros.

Por fim, quando perguntados se sentiam algum tipo de "pressão" em relação à aprovação, seja nos vestibulares ou nos concursos, $45,2 \%$ dos alunos responderam que a pressão advém de suas famílias e do meio social. Uma explicação para esse fenômeno seria em torno da ideia de cobrança e o clima de competição gerado para que os jovens saiam do ensino médio logo com "os pés" em uma nova instituição de ensino que irá moldálo, formá-lo para seguir uma profissão. O jovem deve lidar com toda essa pressão e, por isso, sofre com incertezas e inseguranças para cumprir as expectativas de sua família e da sociedade, criando um ambiente de muita ansiedade para o candidato.

A coordenadora pedagógica relata que encontrou, algumas semanas antes da realização do ENEM, uma das alunas "em um alto nível de ansiedade". Após acolhê-la e buscar entender o motivo da ansiedade, a discente respondeu que "estava desesperada e que não conseguia mais lembrar os conteúdos das disciplinas". Em momento posterior, a coordenadora encontrou-a saindo da aula antes do horário normal, com a justificativa de que iria ao psiquiatra "para pegar a receita de um remédio para controlar sua ansiedade $e$ melhorar sua concentração". 
Esses acontecimentos se repetem com um grande número de alunos do cursinho, conforme informa a coordenadora pedagógica, o que é realidade também país afora. Este fato remete à ideia da produção em larga escala de sofrimento humano e, especificamente, de estresse que antecede as provas. Pode-se afirmar ainda, que os jovens que prestam vestibular para Medicina (caso da aluna em questão) e outros cursos mais concorridos estão mais sujeitos a esse quadro que afeta a saúde deles. Eles se preocupam constantemente com os conteúdos e, muitas vezes, mudam seus hábitos e rotinas visando à aprovação nas provas vindouras. Nesse sentido, a última pergunta do questionário se referia à existência de pressão pelo resultado positivo por parte deles mesmos, ao que $87,1 \%$ dos alunos responderam positivamente.

A resposta de caráter médico e medicamentoso a problemas como o vivenciado por esses estudantes indicam o incremento do fenômeno da medicalização da vida e da educação à medida que se pode compreender que a disputa pelo acesso a cursos de graduação e a carreiras militares produz sofrimento humano com evidentes efeitos na saúde de indivíduos. Assim, é de se concordar com autores que argumentam em prol da ideia de que diversas questões de ordem social e política estão sendo convertidas para o campo individual num constante processo de redução dos fenômenos humanos a processos bioquímicos (Guarido, 2010; Moysés \&Collares, 2013, 2014; Figueira \&Caliman, 2014). A partir disso, o uso de psicofármacos como solução de problemas humanos e sociais que se passou a identificar como doença assume estatuto de verdade e se instala cada vez mais na sociedade e na educação.

\section{Prática pedagógica e relação professor-aluno}

O processo de escolarização ocorre sempre em determinadas condições ambientais. Assim, Tanamachi e Meira (2003) afirmam, a partir da abordagem do materialismo histórico dialético, que as condições objetivas, que são determinadas histórica e socialmente, constroem o mundo subjetivo dos indivíduos. Do mesmo modo, estas condições estão na base da compreensão das práticas sociais, inclusive das práticas pedagógicas. Afinal, "o sujeito postulado pela psicologia histórico-cultural é produto do desenvolvimento de processos físicos e mentais, cognitivos e afetivos, internos (constituídos na história anterior do sujeito) e externos (referentes às situações sociais de desenvolvimento em que o sujeito está envolvido)." (Oliveira \&Rego, 2003, p. 19).

De acordo com os estudos de Bacchetto (2003), pode-se notar que os alunos de cursinhos consideram os métodos escolhidos pelos professores para ministrar suas aulas como positivos e que contribuem para a identificação deles com os conteúdos. Além disso, o número maior de recursos disponibilizados aos professores também contribui para o estreitamento da relação professor-aluno, por muitas vezes gerar um maior interesse dos estudantes e a abertura dos professores para a interação mais próxima com eles.

Tal proximidade fica evidente na instituição pesquisada quando se observa que as relações constituídas entre os professores e alunos são "positivas" à medida que os alunos se mostram à vontade para fazerem perguntas, tirar dúvidas, "brincar" e comentar outros assuntos além daqueles restritos à sala de aula. Também a coordenadora pedagógica do cursinho relata que os alunos têm "total abertura para falarem sobre seus professores; sobre a qualidade das aulas; sobre o cumprimento, por parte dos profissionais, do que é previsto nos editais de concursos e do ENEM; contudo, não é possível afirmar que isso é praticado." Ela diz também que os alunos respeitam as características de cada um dos professores, sendo que alguns são considerados "mais sérios e outros, mais abertos". A profissional conclui que essas especificidades intensificam o interesse dos alunos em aprender e, para Tapia (2003), este 
é um dos mais importantes elementos para o desenvolvimento satisfatório do processo ensino-aprendizagem.

Outro aspecto identificado na prática pedagógica que estreita a relação professoraluno se explicita numa situação observada em uma aula em que um aluno se manifestou sobre uma questão de um simulado (montado pela própria instituição a partir de provas aplicadas no ENEM e de vestibulares de diversas universidades) que estava sendo corrigido coletivamente e que o professor estava criticando por considerá-la mal elaborada. "É, mas essa questão caiu no nosso simulado", disse o aluno. O professor, por sua vez, posicionou-se dizendo que "se for preciso, entramos com um recurso se uma questão parecida como esta cair em um vestibular", visto que ele entendia que se tratava de "uma questão infeliz. É atual, mas foi errada. A interpretação indicaria uma alternativa errada para vocês". Portanto, o profissional colocou-se ao lado dos alunos, tranquilizando-os.

Nessa mesma direção, em uma aula de outra disciplina, enquanto resolviam uma questão, alguns alunos tiveram dúvida sobre a alternativa correta e não concordaram com aquela indicada como tal. Dois alunos, que haviam obtido o resultado correto, explicaram aos demais como haviam chegado ao resultado final. A professora aproveita para indicar que se atentem a esse tipo de questão: "Esse tipo é de assustar, mas normalmente eles não são os piores, né? Mas quando quiserem treinar, podem me falar que eu trago mais." Ou seja, coloca-se à disposição para auxiliar no processo de aprendizagem dos seus alunos.

Outra situação observada foi a de uma aula sobre tipos de gráficos. Antes de começarem a falar sobre o número de habitantes e crescimento populacional, o professor disse: "Não precisam decorar! Esse tipo de prova de vocês não pede isso." Em seguida, ele expõe diferenças entre países povoados e populosos. "Fiquem atentos porque numa prova sempre vai vir os dados do país no gráfico." Ao tratar sobre as diferenças de quantas pessoas nascem e quantas morrem, ele deu outra dica: "Não precisa decorar a fórmula sobre a taxa de natalidade e mortalidade." Além de dar dicas e falar de "macetes", o que é bem comum na prática de todos os professores, a todo momento este professor descontraía a turma por meio de piadas e comparações jocosas que, por sua vez, devolvia as brincadeiras.

Muito comum também é o cuidado dos professores com o ritmo de execução das atividades e de aprendizagem dos alunos. Numa dada aula, por exemplo, a professora senta-se mais próxima a quatro alunos que não haviam terminado uma tarefa, direciona a atenção para cada um deles, pergunta se eles têm dúvidas, se saberiam resolver sozinhos novamente a questão e se poderia passar para a próxima. É comum também que interrompa a sua explicação para responder as dúvidas dos alunos.

Esses extratos do cotidiano das turmas observadas corroboram com a afirmação de Tapia (2003) de que os professores de cursos preparatórios são vistos como aqueles que se preocupam com a aprovação do aluno e, por isso, promovem aulas dinâmicas e descontraídas. Nesse sentido, percebe-se em ambas as turmas participantes desta pesquisa o uso constante pelos docentes das estratégias de dar dicas e oferecer "macetes" aos discentes para memorização de conteúdos de modo que venham a responder corretamente as questões das provas. Isso é tão evidente em cursinhos, que Whitaker, Paiva e Onofre (2008) afirmam que eles são vistos como a "salvação" dos alunos.

Essa realidade cria um dualismo acerca das características dos professores das escolas e dos cursinhos, que se evidencia na maneira diferenciada de transmitir o conhecimento. $\mathrm{Na}$ escola, o professor está preocupado que a aprendizagem se estenda por toda a vida do aluno (aprenda para a vida) e, no cursinho, ele espera que o aluno detenha o conhecimento até o dia da prova (aprenda para ser aprovado). 
Por isso, no caso dos cursinhos, o docente utiliza técnicas que envolvem memorização "pura e simples", como as "aula-show" e até paródias que usam conteúdos de matérias como química, física e matemática que envolvem fórmulas, ou biologia que tem muitos nomes, estratégias que não deixam espaço para a discussão, reflexão e "mobilização dos esquemas de assimilação" (Piaget, 1966).

No entanto, a citada pesquisa de Bacchetto (2003) aponta que tais práticas não são capazes de quebrar obstáculos no caso de cursinhos que atendem um grande número de alunos, pois ainda que os métodos e práticas procurem alcançar a todos, o professor não pode ter acesso às dificuldades particulares de cada deles. Nesse sentido, o contexto em que a investigação ocorreu se diferencia, uma vez que as turmas são pequenas, o que possibilita, inclusive, que os professores se refiram e conversem com seus alunos dizendo os nomes deles, além de demonstrarem, em alguns momentos, ter conhecimento sobre os seus avanços, erros e acertos.

Ainda em relação ao professor que atua na preparação para processos seletivos, sabese que eles são intensamente cobrados, uma vez que, o acesso dos alunos à Universidade é relacionado ao que estes aprenderam durante o tempo que frequentaram os cursinhos. Além disso, bons resultados (índice elevados de aprovação) possibilitarão que disponham de melhores salários e recursos para desenvolver seus trabalhos durante as aulas (Santos, 2004). Considerando ainda, que os alunos matriculados nos cursinhos estão inclinados ao estudo e dedicação, é gerado um "clima" de identificação e proximidade entre professoraluno e a ideia de que os docentes "são profissionais preocupados com a realidade social na qual o estudante está inserido e com suas dificuldades de aprendizagem." (Santos, 2004, p. 177).

De um modo geral, baseando-se nas observações realizadas, pode-se concordar com Santos (2004) quando ela escreve que a identidade do professor que atua em cursinhos é a de um profissional da educação que traça sua carreira a partir do seu desempenho e do impacto que exerce sobre os seus alunos e, consequentemente, suas aprovações. Acrescenta-se que tal caráter contribui para uma relação positiva e "leve" entre professoraluno nesse espaço à medida que ambos, professor e aluno, estão focados no resultado almejado e há uma cooperação para tal.

Enfim, o estilo de aula observado na prática pedagógica dos professores da instituição aonde este estudo foi realizado se caracteriza pela repetição, uso de dicas, esquemas, uso de PowerPoint, "macetes", entre outras estratégias. Esse estilo tem um efeito rápido e prático na retenção de conteúdos necessários. Isso chama a atenção dos jovens que estão ali, visto que, diferentemente do professor de escola, o professor de cursinho está sujeito a uma organização de ensino privado, na maioria das vezes, que disponibiliza o material e outros recursos. Espera-se que o professor repasse os conhecimentos, indicando os melhores meios para aplicar os conceitos, fórmulas e conteúdos durante a prova (Santos, 2004).

\section{Considerações finais}

Notadamente, os cursos preparatórios para o ENEM, vestibulares e concursos públicos representam uma área de trabalho para professores que cada vez mais se expande. Estes são convocados a dispor seus conhecimentos e dividi-los em conteúdos úteis que serão aplicados de acordo com os objetivos almejados por seus alunos. Trata-se, portanto, de um ensino e aprendizagem marcadamente pragmático e utilitarista. Enfim, evidencia-se que "A atividade educacional em sala de aula se constrói nas e pelas relações sociais; por isso há uma clara correspondência entre a qualidade das práticas pedagógicas e os diferentes tipos de relações interpessoais que se estabelecem cotidianamente entre professores e alunos." (Meira, 2003, p. 25).

Pode-se dizer, então, que os métodos e 
práticas pedagógicas adotadas pelos professores interferem diretamente na satisfação dos alunos com os cursinhos e na identificação deles com seus professores à medida que ambos estão voltados para o sucesso nos intentos competitivos que os estudantes empreendem na busca tanto por cursos de graduação quanto por carreiras públicas, inclusive as militares, como foi discutido na presente pesquisa. Fica evidente que essa identificação em geral se diferencia da relação que é estabelecida por professores e alunos em escolas e se torna uma marca dos cursinhos, o que lhe garante como instituição necessária numa sociedade em que o acesso ao ensino superior não é universal e que o emprego público é muito desejado porque é sinônimo de estabilidade profissional num cenário de grande índice de desemprego.

O presente estudo pretende oferecer uma contribuição aos docentes, discentes e outros que se interessam e lidam direta ou indiretamente com as questões que envolvem a prática pedagógica em cursos preparatórios. Espera-se também, que este trabalho sirva de inspiração para sua replicação ou desenvolvimento de novas investigações, especialmente na Educação Superior, principalmente porque os cursinhos se constituem como organização relativamente nova - se considerarmos a sua configuração atual, principalmente após a criação do ENEM e o boom de concursos públicos - e a literatura científica sobre o tema é escassa, tanto no que se refere às práticas pedagógicas e relações desenvolvidas quanto no que diz respeito à inserção do psicólogo escolar e educacional nessas instituições educacionais.

Por último e não menos importante, aponta-se a ausência de documentos no Centro de Referência Técnica em Psicologia e Políticas Públicas (CREPOP) quanto ao exercício do profissional psicólogo no campo emergente dos cursos preparatórios. No documento "Referências técnicas para Atuação de psicólogas(os) na Educação Básica" (Conselho Federal de Psicologia, 2013) os cursinhos não são contemplados. Por se tratar de uma estrutura do Conselho Federal de Psicologia (CFP) que cumpre o papel de produzir parâmetros técnicos, éticos e políticos para a atuação do psicólogo em âmbito nacional, essa lacuna na produção das referências se torna ponto a ser destacado como um desafio.

Ainda no contexto do CFP, existe uma publicação que sintetiza as discussões e encaminhamentos realizados no "Seminário Nacional do Ano da Psicologia na Educação: profissão na construção da Educação para todos" (Conselho Federal de Psicologia, 2009), realizado de 24 a 26 de abril de 2009. Nela, se reconhece a abertura de novos lugares para a atuação do psicólogo escolar, visto que ele "vem sendo chamado a atuar em (...) ambientes formais ou não convencionais, comprometidos e investidos da função educativa, como creches, abrigos, associações, organizações não governamentais (ONGs), cursinhos preparatórios [grifo nosso], (...) e diversas instituições (...) de cunho educativo" (p. 85). Entretanto, não há parâmetros para o trabalho do psicólogo junto a estes contextos nem nos documentos do CREPOP, como dito, nem nesta publicação, ainda que a demanda em organizações educativas seja grande e variada: orientação profissional, apoio à saúde mental do estudante (que enfrenta problemas nessa época como a ansiedade), orientação à equipe de professores e demais funcionários, trabalho com as dificuldades do processo de escolarização (que envolve o processo ensinoaprendizagem) etc.

Nesse sentido, Tanamachi e Meira (2003, p. 26) definem que "A atuação do psicólogo deve visar uma multiplicidade de ações, uma vez que a identidade profissional está nas finalidades a serem atingidas por recursos teóricos e práticas diferenciadas". Entendem, assim, que os conhecimentos psicológicos têm o potencial de contribuir para a elaboração de propostas pedagógicas mais consistentes que promovam melhorias no processo ensino-aprendizagem. Portanto, o trabalho dos psicólogos escolares e educacionais "situa-se no compromisso claro 
com a tarefa de construção de um processo educacional qualitativamente superior. Portanto, sua função social não poderia ser outra: contribuir para que a escola cumpra de fato seu papel de socialização do saber e de formação crítica." (Meira, 2003, p. 57).

Esse compromisso ético-político independe do espaço de atuação do psicólogo, pois se não é comum a presença deste profissional em cursos preparatórios, há de se considerar que, além da possibilidade destes contratarem serviços psicológicos, os profissionais da Psicologia recebem demandas provenientes destes cursos, como por exemplo, alunos com queixas escolares nos consultórios, clínicas e serviços públicos de saúde. Concordando com esse argumento, Meira (2003, p. 60) entende que o psicólogo escolar - e pode-se ampliar, para qualquer área de atuação da Psicologia independentemente de trabalhar dentro ou fora da escola deve assumir um compromisso teórico e prático com as questões da educação.

\section{Referências}

Abramovay, M., \&Castro, M. G. (Coords) (2003). Ensino Médio: Múltiplas vozes. Brasília: MEC, UNESCO.

Bacchetto, J. G. (2003). Cursinhos prévestibulares alternativos no município de São Paulo (1991-2000): A luta pela igualdade no acesso ao Ensino Superior (Dissertação de Mestrado). Universidade de São Paulo.

Bayma-Freire, H., Roazzi, A., \& Roazzi, M. M. (2015). O nível de escolaridade dos pais interfere na permanência dos filhos na escola. Revista de Estudios e Investigación en Psicología y Educación, 2(1), p. 35-40.

Bonfim, T. A. (2003). O CAPE em nossas vidas: A visão de um grupo de alunos, exalunos e colaboradores sobre um curso pré-vestibular gratuito (Dissertação de Mestrado). Universidade de São Paulo, Ribeirão Preto.

Canevacci, M. (2008). Fetichismos visuais: Corpos erópticos e metrópole comunicacional. Cotia: Ateliê Editorial.
Conselho Federal de Psicologia (2009). Seminário Nacional do Ano da Educação Psicologia: Profissão na construção da educação para todos. Brasília: Autor.

Conselho Federal de Psicologia (2013). Referências técnicas para atuação de psicólogas(os) na Educação Básica. Brasília: Autor.

Falkembach, E. M. F. (1987). Diário de campo: Um instrumento de reflexão. Contexto Educação, 2(7), p. 19-24.

Fiamengue, E. C. (2002). Mas, afinal que Elite é essa? Elitização/deselitização no vestibular VUNESP (Tese de Doutorado). Universidade Estadual Paulista, Araraquara.

Figueira, P., L.; \&Caliman, L. V. (2014). Considerações sobre os movimentos de medicalização da vida. Psicologia Clínica, 26(2), p. 17-32.

Gil, A. C. (2008). Métodos e técnicas de pesquisa social (6 Ed.). São Paulo: Atlas.

Guarido, R. A. (2010). Biologização da vida e algumas implicações do discurso médico sobre a educação. In Conselho Regional de Psicologia, \& Grupo Interinstitucional Queixa Escolar (Orgs), Medicalização de crianças e adolescentes: Conflitos silenciados pela redução de questões sociais a doenças de indivíduos, p. 27-39. São Paulo, SP: Casa do Psicólogo.

Guimarães, S. (1984). Como se faz a indústria do vestibular. Petrópolis, RJ: Vozes.

Günther, H. (2003). Como elaborar um questionário: $N^{o} 1$ (Série planejamento de pesquisa nas ciências sociais). Brasília: UnB, Laboratório de Psicologia Ambiental.

Instituto Nacional de Estudos e Pesquisas Educacionais (INEP) (2015). Sinopse $d a$ Educação Superior 2015. Recuperado de http://inep.gov.br/sinopses-estatisticas-daeducacao-superior

Lei $\mathrm{n}^{\circ}$ 5.540/1968 (1968). Fixa normas de organização e funcionamento do ensino superior e sua articulação com a escola média, e dá outras providências. Diário Oficial da União - Seção 1 (29-11-1968), 10369.

Lei $\mathrm{n}^{\circ}$ 9.394/1996 (1996). Estabelece as diretrizes e bases da educação nacional. 
Recuperado de

http://www.planalto.gov.br/ccivil_03/leis/L 9394.htm.

Lei $\mathrm{n}^{\circ} 12.711 / 2012$ (2012). Dispõe sobre o ingresso nas universidades federais e nas instituições federais de ensino técnico de nível médio e dá outras providências. Recuperado de http://www.planalto.gov.br/ccivil_03/_ato2 011-2014/2012/lei/112711.htm.

Martins, J. B. (1996). Observação participante: Uma abordagem metodológica para a psicologia escolar. Semina: Ciências, Sociedade e Humanidade, 17(3), p. 266273.

Meira, M., E., M. (1998). Desenvolvimento e aprendizagem: Reflexões sobre suas relações e implicações para a prática docente. Ciência \& Educação, 5(2), p. 6170.

Meira, M. E. M (2003). Construindo uma concepção crítica de psicologia escolar: Contribuições da pedagogia históricocrítica e da psicologia sócio-histórica. In: M. E. M. Meira \&M. A. M. (Orgs), Psicologia Escolar: Práticas críticas (p. 13-79). São Paulo: Casa do Psicólogo.

Moysés, M. A. A., \&Collares, C. A. L. (2013) Medicalização: $\mathrm{O}$ obscurantismo reinventado. In: M. A. A. Moysés, C. A. L. Collares, \&M. C. F. Ribeiro, M. C. F. (Orgs), Novas capturas, antigos diagnósticos na era dos transtornos (p. 4164). (1 Ed.) Campinas: Mercado de Letras.

Moysés, M. A. A., \&Collares, C. A. L. (2014). Mais de um século de patologização da educação. Fórum: Diálogos em Psicologia, 1(1), p. 51-64.

Nepomuceno, R. F., \& Witter, G.P (2010). Influência da família na decisão profissional: Opinião de adolescentes. Revista da Associação Brasileira de Psicologia Escolar e Educacional, 14(1), p. 15-22.

Oliveira, L. L. (2013). Urbanização e acesso ao ensino superior. Cadernos de Pesquisa, (17), p. 53-68.

Oliveira, M. K.; \& Rego, T. C. (2003). Vygotsky e as complexas relações entre cognição e afeto. In: V. A. Arantes (Org.),
Afetividade na escola: Alternativas teóricas e práticas, p. 13-34. São Paulo: Summus.

Pezzi, A. C. (2002). Cursinhos: Um rito de passagem. In: R. M. Andrade \& E. F. Fonseca (Orgs), Aprovados!: Cursinho prévestibular e população negra, p. 63 -73. São Paulo: Selo Negro.

Piaget, J. (1966). Seis estudos de psicologia. Rio de Janeiro: Forense.

Portal Brasil (2014). Carreira nas Forças Armadas atrai mais mulheres. Recuperado de http://www.brasil.gov.br/cidadania-ejustica/2014/06/carreira-nas-forcasarmadas-atrai-mais-mulheres.

Roese, A., Gerhardt, T. E., Souza, A. C.; \& Lopes, M. J. M. (2006). Diário de campo: Construção e utilização em pesquisas científicas. Online brazilian journal ofj. Nursing (Online), 5(3). Recuperado de http://www.objnursing.uff.br/index.php/nur sing/rt/printerFriendly/598/141

Raupp, F. M. \& Beuren, I. M. (2003). Metodologia da pesquisa aplicável às ciências sociais. In: I. M. Beuren (Org.), Como elaborar trabalhos monográficos em contabilidade: Teoria e prática, p. 76-97. São Paulo: Atlas.

Santos, C. A. (2004). Identidade profissional do professor do Cursinho Garra de Goiânia (Dissertação de Mestrado). Pontifícia Universidade Católica de Goiás, Goiânia.

Silva, I. D. C. (2012). "Passei na UFRGS": O imperativo da aprovação veiculado em materiais midiáticos de cursinhos prévestibulares. (Dissertação de Mestrado). Universidade Federal do Rio Grande do Sul, Porto Alegre.

Tanamachi, E. R., \&Meira, M. E. M. (2003). A atuação do psicólogo como expressão do pensamento crítico em Psicologia e Educação. In: M. E. M. Meira \&M. A. M Antunes (Orgs), Psicologia escolar: Práticas críticas (p. 11-62). São Paulo: Casa do Psicólogo.

Tapia, J. A. (2003). Motivação e aprendizagem no ensino médio. In: C. Coll (Org.), Psicologia da aprendizagem no Ensino Médio, p. 103-139. Porto Alegre: Artmed. 
Vieira, A. C. S., \& Rava, P. G. S. (2010). Ninho cheio: Uma nova etapa do ciclo vital familiar? Barbarói, (33), p. 118-134.

Whitaker, D. C. A. (2010). Da "invenção" do vestibular aos cursinhos populares: Um desafio para a Orientação Profissional. Revista Brasileira de Orientação Profissional, 11(2), p. 289-297.

Whitaker, D. C. A., \&Fiamengue, E. (1999). 10 anos depois: UNESP: Diferentes perfis de candidatos para diferentes cursos: Vol. 11 (Série pesquisa Vunesp). São Paulo: Fundação Vunesp.

Whitaker, D. C. A., \& Fiamengue, E. (2001). A heterogeneidade sócio econômica vestibulandos dos diferentes cursos da UNESP a partir de algumas variáveis de capital cultural: Vol. 17 (Série pesquisa Vunesp). São Paulo: Fundação Vunesp.

Whitaker, D. C. A., Paiva, F. N., \&Onofre, S.

A. (2008). Cursinhos comunitários, esperança e desalento: um estudo de caso em assentamentos de reforma agrária (Araraquara-São Paulo). In: A. V. M. Fernandes, C. P. D. Almeida, \&D. C. A. Whitaker (Orgs), Educação, juventude e políticas públicas: Reflexões sobre inclusão e preconceito, p. 35-50. São Paulo: Cultura Acadêmica.

Dados sobre os autores:

- Celso Francisco Tondin é graduado em Psicologia pela Universidade do Vale do Rio dos Sinos. Mestre em Psicologia pela Universidade Federal de Minas Gerais. Doutor em Psicologia pela Pontifícia Universidade Católica do Rio Grande do Sul. Professor do Departamento de Psicologia e do Programa de Pós-Graduação em Psicologia da Universidade Federal de São João Del-Rei.

- Larissa Medeiros Marinho dos Santos é graduada e licenciada, mestra em Psicologia Social e do Trabalho e doutora em Psicologia pela Universidade de Brasília. Professora do Departamento de Psicologia e do Programa de Pós-Graduação em Psicologia da Universidade Federal de São João Del-Rei.
- Deruchette Danire Henriques Magalhães é graduanda em Psicologia pela Universidade Federal de São João Del-Rei (UFSJ).

- Jacqueline Danielle Pereira é graduanda em Psicologia pela Universidade Federal de São João Del-Rei (UFSJ). 